\title{
Analysis on the Key Factors Influencing the Success of the Industry-University Collaborative Innovation
}

\author{
Jia Liu ${ }^{1, a^{*}}$ and Yuanjian Qin ${ }^{1, b}$ \\ ${ }^{1}$ Wuhan University of Technology, China \\ a1148472945@qq.com, bqyjhb@163.com
}

Keywords: Collaborative innovation; Key factor; Innovation project; R\&D

\begin{abstract}
The research on the industry-university collaborative innovation has always been the focus. However, more attention is paid to the cooperative innovation mechanism and the role of the main body, but less to the key influencing elements of collaborative innovation. By using the method of case study, analysis the collaborative innovation projects carried out by BT Research Institute, constructing the key factors model of the success of the cooperative innovation project, exploring the key influencing elements of collaborative innovation. The results showed that: the executive director's insight, the key node inspection, the distribution of benefits is the key factor affecting the success of the collaborative innovation.
\end{abstract}

\section{Introduction}

Collaborative innovation is the enterprise, university and scientific research institutions to establish collaborative innovation platform, facilitate the knowledge creation, $\mathrm{R} \& \mathrm{D}$, technology transfer and application [1]. The industry-university collaborative innovation aim at promoting the close integration of the innovation subjects. Through integrate superior resources, to promote the interaction between innovation subjects and achieve continuous innovation. However, compared with developed countries, collaborative innovation performance output is not high in our country [2].

On the basis of previous research results, we analysis the problems in the collaborative innovation project of BT Research Institute, and research on various factors influencing the success of collaborative innovation project, in order to discover the key factors affecting success.

The key success factors theory that several limited factors in the organization must be very good to completed for the organization achieving good performance. The industry-university collaborative innovation is a talent intensive activity, so most of the participants were "knowledge workers". Compared with other categories of projects, its management is more difficult and complex and the effect on innovation performance is more significant. In order to achieve good performance, managements should identify and manage the key factors [3]. This study explores the key factors of the success of collaborative innovation from the perspective of project management, to help managers to achieve effective management of the projects.

\section{Literature Review}

Standard Definition of Collaborative Innovation Project Success. Project success criteria are the principles and guidelines that are used to judge the success of a project. The success criteria of the project have the following points. Early researchers believe that time, cost, and quality are the basic criterion for project success that is a project in a predetermined time by the budget to complete and achieve the quality is successful. Some scholars have put forward to the dynamic development of the vision to evaluate the success of the project; the satisfaction of all key personnel (customer, project team and customer) is combined together, as the addition of success. Shenhar using qualitative and quantitative methods put forward 4 criteria for the success of the project: project efficiency, direct management and organizational success, the impact on customers, long-term development [4]. Westerveld assess the project success from the respect of project result, project 
member evaluation, user evaluation, customer evaluation, evaluation of the project partners and other important stakeholders. Jinan Wang defines the success of the project from R \& D project quality standards, project progress standards and R \& D project stakeholder satisfaction standards. This study consider the success of the project criterion contain the possibility of project implementation, project quality standards and the satisfaction of the parties.

The Key Elements of Collaborative Innovation Project Success. Based on the theory of project management, team, personnel, technology, process and other elements are reflected in the management environment. Managers can not directly manage technology and other objective factors, must start from stakeholders. So this research regard project leader, project team, project process management, project benefit distribution as the criterion of success. These factors are manageable.

Previous studies show that Project leader can significantly improve the team performance as the key components of project implementation and scarce human capital. The research on the influence of the project leader on the project performance is mainly focused on the competency. For example, Feng Ming divided the quality of project leader own factors into knowledge and skills, personality and behavioral characteristics, motivation and needs [5]. C. H. Fang deem the technical developer should have the personality characteristics and the key ability, such as the level of education, professional knowledge, etc. Wang Jinan believes that the project leader should have the following capabilities: ability to grasp the technical route of $\mathrm{R} \& \mathrm{D}$ project; the ability and innovative ability to solve key technical problems. So, this study believes that the academic ability and innovation ability is the core ability of the project leader [6]. Besides, the implementation of the project is also restricted by the level of management. Weiwei $\mathrm{Wu}$ believes that the indirect and direct effect of technology management capability on $\mathrm{R} \& \mathrm{D}$ activities is equally important. So, the factors also include market insight and relationship processing capabilities [7].

Project team is the main commitment to innovation activities, the ability and attitude of the project has a direct impact on project performance. Joyce Fortune and Diana White consider project team ability is the key factor and necessary condition of project success. Mahmood Hussain posit the common goal of the organization is be beneficial to improving the team performance. Wang Jinan regards the common goal, research and development team, teamwork culture as the key success factors. So, we divided the team factor into team structure, team ability and team cohesion.

The realization of the strategic objectives of the industry-university collaborative innovation through the project. The progress of the project restricts the realization of the goal of collaborative innovation. Xiaolan Liu from five aspects of the management explore university research projects, such as the project start, project development, project execution, project monitoring and project closure, and put forward to establish the enterprise of the university research project management mechanism of specific measures [8]. In this study, the project process management factors can be divided into 4 dimensions: plan management, operation management, key nodes inspection and acceptance management.

The interest distribution of the industry-university collaborative innovation refers to the provisions on the distribution of benefits before the start of cooperation. Kefan Xie demonstrates the $\mathrm{R} \& \mathrm{D}$ investment subsidies from industry to university on the impact of the overall R \& D costs based on the model of game theory. The results show that according to the fixed proportion of product sales revenue is better than a one-time transfer of the way [9]. Biao Dong take the systematic research on the content of cooperative interests and its distribution, through tracking research on the domestic and foreign research cooperation and the status of interest distribution [10]. Combined with the practice of our country, analyze the distribution of benefits and the proportion of interest distribution, and emphasize the role of the government in the distribution of the interests of the industry-university collaborative innovation. In this study, the distribution of benefits can be divided into 3 dimensions: the interests of the composition, the mode of interest distribution, the proportion of interest distribution. So, the key factor model of the collaboration innovation project is the following figure: 


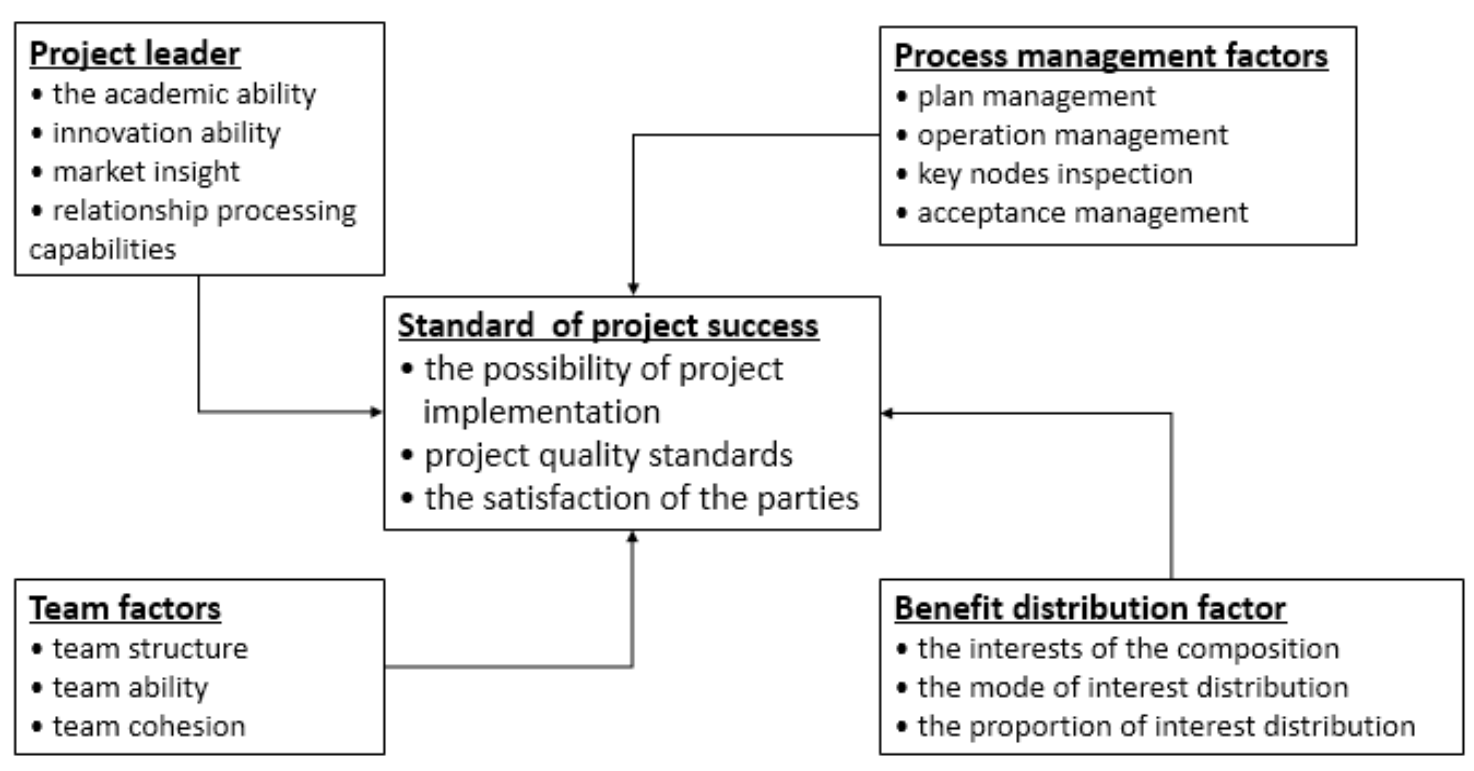

Figure 1. Research mode

\section{Method}

This paper adopts case study method; the reason is that the study of this paper is to explore what factors affect the success of the project. Need to go deep into the project to explore what the key elements will affect the success of the project. Based on the research of collaborative innovation project process research, complete empirical analysis to be further strengthened. Case studies are particularly applicable to new research areas or areas of inadequate research.

The data sources of this study mainly include two aspects: (1) Discussion with the staff of the institute. We have a discussion with the relevant personnel spending 1-2 hours, the relevant personnel contain the main leadership of the institute, research and development center director and project leaders. Discussion questions involving the selection of the project, the project process, resource allocation, management, process management and other aspects; (2) Research on relevant documents. Mainly includes 3 categories, namely the project related information, the successful case and the failure case, the Research Institute's development process and the cooperation case.

\section{Case Analysis}

Case Description. The BT Research Institute was founded in 2012. The Research Institute combined with local practice, established the development strategy of "relying on local resources and industrial advantages, develop the emerging industries and facilitate the resource industry and traditional industry upgrading". The Institute has set up 12 research institutes with several universities, a highly efficient innovation system already formed which supported by a number of high level universities.

Since the establishment of the BT Research Institute, have set up the project 34 items in total, currently has the world's leading level of advanced technology 18 has been completed and developed, and successfully set up business or to achieve the transfer of technology. In this paper, regard the projects carried out by the Research Institute as the research objects. Analyze the success and failure of projects, and identify the key elements of the impact.

Critical Success Factors Analysis. BT Research Institute to carry out the project with the academic director and the executive director jointly participation of the matrix management model. Applicant as academic director pay attention to academic research and forecast the project technical direction. The executive director is recommended by the institute or academic director, they pay attention to daily management, project execution management, and undertake the due obligations for the results of the project, the management of the use of funds. 
BT Research Institute has been commissioned to research the light-emitting materials. The project has received national support, have good market outlook and high technical maturity. R \& D activities have been successful, but industrialization has failed. Because it does not take into account the entry of the industry is very high, leading to the industrialization can't be achieved, coupled with the error understanding of market trends. The main reason for the failure of the project is the project leader no necessary abilities. Ranking and analyzing the failure cases, we find that technology is no problem which can produce samples or products, but into the market the problems have arose. So, the success of the collaborative innovation projects, not only the academic ability and innovative ability of academic director, but the market insight of executive director is essential.

If the $\mathrm{R} \& \mathrm{D}$ team have problem in the structure, will lead to research and development activities can't be carried out normally. R \& D activities require the parties to contribute their own strength, if an individual's ability is insufficient, it will affect the success of the project. Group cohesion refers to the intention and behavior of the staff to cooperate with each other, lack of trust between each other will restrict the development of the projects. Through comparison we found that the successful project's team building is relatively good.

Through case analysis, we find that the key nodes inspection in project management is critical to the final success of the project. By checking we can modify the technical roadmap to ensure that research and development work is always on the right path. During the process, how to get the final benefit is a key factor to control the late industrialization. The allocation scheme requires all parties to accept, so as to avoid unnecessary disputes.

\section{Summary}

Innovation activities need professional management team, training professional project management team is essential to the success of the project. Effective management can stimulate the initiative and creativity of the technical staff. Research institutes should invest resources to train personnel who understand both technical and management. Pay much attention to the process management of the project. Process management restricts the progress of the project, which should be paid more attention to. Build collaborative and efficient collaborative innovation project team. Good team can play multiple effects.

\section{References}

[1] H.Y. He. Theoretical model of cooperative research and development [J]. Science Research, 2012, 30 (2): 165-174. (In Chinese)

[2] N. Zhang. Research on comprehensive evaluation of project management risk of industry university research cooperation [D]. Ji'nan: Shandong University, 2014. (In Chinese)

[3] J.A. Wang and R.G. Ding. An empirical study on the key success factors of the cooperative R \&amp; D project [J]. Scientific and Technological Progress and Countermeasures, 2015, 32 (20): 7-11. (In Chinese)

[4] AARON J, SHENHAR. Project Success: multidimensional strategic concept [J]. Long Range Planning, 2001(34):699-725.

[5] M. Feng. And Y.J. Wang. Analysis of influencing factors of managerial competency structure[J]. Science of Science and Management of S. \&T, 2007, 28 (2): 142-147. (In Chinese)

[6] C H FANG, Y C KANG, G L CHEN, Y S CHENG. Study on personality traits and key competence of R\&D staff: an empirical analysis in Taiwan[C]. Proceedings of the 2008 IEEE, 2008.

[7] S.H. Zhao. And X.L. Liu. Study on the project management system of University Research Institute of enterprise management [J]. Journal of Xinxiang College, 2016, 02: 67-70. (In Chinese)

[8] E WESTERVELD, The project excellence model: linking success criteria and critical success factor [J].International Journal of Project Management, 2003(6):411-418.

[9] K.F. Xie and H.L. Liu. Research and development entity game analysis [J]. Science of Science 
and Management of S. \&T, 2006, 10:27-30-109. (In Chinese)

[10] Y.D. Wang and B. Dong. Research on the benefit allocation method based on model of industry university research cooperation [J]. Science-Technology and Management, 2006, (1): 112-121. (In Chinese) 